\title{
Multicomponent Program to Reduce Functional Decline in Frail Elderly People: A Cluster Controlled Trial
}

\author{
Franca G.H. Ruikes, MD, Sytse U. Zuidema, MD, PhD, Reinier P. Akkermans, MSc, \\ Willem J.J. Assendelft, MD, PhD, HenkJ. Schers, MD, PhD, and \\ Raymond T.C.M. Koopmans, MD, PhD
}

Background: The increasing number of community-dwelling frail elderly people poses a challenge to general practice. We evaluated the effectiveness of a general practitioner-led extensive, multicomponent program integrating cure, care, and welfare for the prevention of functional decline.

Methods: We performed a cluster controlled trial in 12 general practices in Nijmegen, the Netherlands. Community-dwelling frail elderly people aged $\geq 70$ years were identified with the EASY-Care twostep older persons screening instrument. In 6 general practices, 287 frail elderly received care according to the CareWell primary care program. This consisted of proactive care planning, case management, medication reviews, and multidisciplinary team meetings with a general practitioner, practice and/or community nurse, elderly care physician, and social worker. In another 6 general practices, 249 participants received care as usual. The primary outcome was independence in functioning during (instrumental) activities of daily living (Katz-15 index). Secondary outcomes were quality of life [EuroQol (EQ5D+C) instrument], mental health and health-related social functioning (36-item RAND Short Form survey instrument), institutionalization, hospitalization, and mortality. Outcomes were assessed at baseline and at 12 months, and were analyzed with linear mixed-model analyses.

Results: A total of 204 participants (71.1\%) in the intervention group and 165 participants (66.3\%) in the control group completed the study. No differences between groups regarding independence in functioning and secondary outcomes were found.

Conclusion: We found no evidence for the effectiveness of a multifaceted integrated care program in the prevention of adverse outcomes in community-dwelling frail elderly people. Large-scale implementation of this program is not advocated. (J Am Board Fam Med 2016;29:209-217.)

Keywords: Aging, Delivery of Health Care, Frail Elderly, Geriatrics, Geriatric Assessment, Interdisciplinary Health Team, Primary Health Care

Population aging has a profound effect on the number of frail elders and is a major challenge for health care systems. Frailty is a condition in which losses in several domains of functioning lead to a declin-

This article was externally peer reviewed.

Submitted 8 July 2015; revised 7 October 2015; accepted 12 October 2015.

From the Department of Primary and Community Care, Radboud University Nijmegen Medical Centre, Nijmegen (FGHR, RPA, WJJA, HJS, RTCMK); the Department of General Practice, University of Groningen, University Medical Centre Groningen, Groningen (SUZ); and the Joachim and Anna Centre for Specialized Geriatric Care, Nijmegen, the Netherlands (RTCMK).

Funding: This trial was funded by the Dutch National Care for the Elderly Program, as initiated by the ing reserve capacity and a subsequently increased vulnerability in functional decline, dependence, hospitalization, institutionalization, and death. ${ }^{1-3} \mathrm{It}$ is thought to be present in up to a quarter of people

Netherlands Organization for Health Research and Development (ZonMW project no. 313050201). Health insurance companies (CZ and UVIT) and the municipality provided additional funding.

Conflict of interest: none declared.

Disclaimer: The funders had no influence on the analysis and reporting of the study.

Corresponding author: Franca G.H. Ruikes, MD, Department of Primary and Community Care, Radboud University Nijmegen Medical Centre, P.O. Box 9101, 6500 HB Nijmegen, the Netherlands (E-mail address: Franca.Ruikes@ Radboudumc.nl). 
aged $\geq 85$ years. $^{4}$ The complex and interacting health care needs of these frail elders can be addressed only in a system that integrates health care and welfare services. This approach is supposed to delay the onset and progression of frailty and prevent its adverse outcomes, including functional dependence and institutionalization. ${ }^{5}$

In countries with a strong primary care system, such as the Netherlands, general practitioners (GPs) provide continuous, person-centered care to community-dwelling frail elderly people. Care delivery is facilitated by the use of high-standard electronic medical records (EMRs) and patient panels, defining the population under care. ${ }^{6,7}$ In the Netherlands, GPs often collaborate with practice nurses in the delivery of care (programs) according to the needs of the practice population. ${ }^{7}$ Moreover, physicians providing geriatric care increasingly operate (as consultants) in caring for frail older people in the community. ${ }^{8}$ However, the coordination between GPs, other primary and specialist care providers, and home care and community services is often perceived to be insufficient, leading to fragmented delivery of care. ${ }^{9}$ Many opinion leaders therefore plea for a redesign of primary care services for frail elders.

In the past 20 years, this perceived need has led to the development of several integrated care programs targeting frail elderly people. Systematic reviews have shown these programs to vary considerably in content, the disciplines involved, intensity, duration, and setting. These studies have shown no or merely modest and inconsistent effects on clinical outcomes and health care utilization, ${ }^{10-12}$ which is disappointing. To date, therefore, there is no conclusive evidence for an efficient and effective approach to redesigning geriatric primary care. In addition to the need for coordinated and integrated care, the need for medication intervention programs aimed at the management of polypharmacy (ie, the [over]use of multiple medications) is widely recognized. ${ }^{13-16}$

In Dutch primary care this has led to a wellsupported belief that community-based geriatric care needs to be multifaceted, combining structured multidisciplinary collaboration between professionals from cure, care, and welfare domains; proactive care planning; case management; and medication review. ${ }^{17}$ Therefore we designed the CareWell primary care program, which combines the above elements and aims for the prevention of functional decline, maintenance of well-being, and prevention of institutionalization and hospitalization among community-dwelling frail elders. This article reports the results of the cluster controlled effectiveness trial.

\section{Methods}

We conducted a 2-arm, nonrandomized, cluster controlled trial in primary care in the municipality of Nijmegen, the Netherlands, between September 2011 and September 2012. To prevent contamination bias, we used a cluster controlled design with allocation by GP practice. ${ }^{18,19}$ Details were published previously. ${ }^{20}$ The study was reviewed by the ethics committee of the Radboud University Medical Centre Nijmegen (registration no. 2010/403) and registered at ClinicalTrials.gov (identifier NCT01499797).

\section{Recruitment}

Eligibility criteria for GP practices were (1) a sufficient number of patients aged $\geq 70$ years on their patient list, (2) adequate practice facilities enabling (future) implementation of the program, and-in the intervention group-(3) a solid motivation to adopt the program to reach optimal implementation. Six eligible GP practices were recruited for participation in the intervention arm and were informed about the program. Then, 6 GP practices were recruited for the control group without being informed about the program. They were explicitly asked to deliver "care as usual" and to decline new relevant interprofessional collaborations during the intervention period. No restrictions were imposed on preexisting collaborations between GPs and (practice) nurses.

GPs in both arms were trained to apply the concept of frailty and to identify study participants using the EASY-Care Two-Step Older Persons Screening (TOS) instrument. ${ }^{21}$ The EASY-Care TOS has shown good construct validity and interrater reliability, and is well accepted by primary care professionals. ${ }^{22,23}$ All practices were instructed to include 50 frail elders aged $\geq 70$ years. Exclusion criteria were admission to a residential or nursing home and/or critical or terminal illness. After the Easy-Care TOS assessment, the GP and practice nurse/research assistant made a final decision on the presence of frailty, based on clinical reasoning using all explicit and tacit information. ${ }^{21}$ In addi- 
tion, the complexity of the care context, representing the organization and coordination of care, was judged. ${ }^{24}$ Frail elders with and without complex care were included. Details on the recruitment of practices and participants have been reported previously. ${ }^{20}$

\section{Intervention}

The CareWell primary care program consisted of 4 key elements: multidisciplinary team meetings, proactive care planning, case management, and medication review.

Each practice assembled a core multidisciplinary team consisting of the GP, the practice nurse (or, if unavailable, a community nurse), an elderly care physician $(\mathrm{ECP})^{8}$, added to the team to secure geriatric expertise and knowledge on proactive care planning, and a social worker with expertise on social and welfare domains. No structural collaborations between GPs, ECPs, and social workers were readily available at the time of the intervention. Team meetings were held every 4 to 8 weeks. In addition, team members were able to communicate virtually through a secure, Web-based health and welfare information portal. ${ }^{25}$

Proactive, individually tailored care plans were formulated for each participant upon enrollment in the program; these plans were based on individual health-related goals and needs as assessed with the EASY-Care TOS. Care plans were revised during the team meetings at least every 6 months and stored in the information portal.

A case manager (either a nurse or social worker) was assigned to each participant. Case managers were responsible for the planning and logistics regarding the team meetings and for coordinating and monitoring care. Furthermore, they were instructed to ensure participants' acknowledgment of the care plans, encourage their involvement in setting goals, and actively maintain treatment contact with the participants (and their informal caregivers) by telephone or home visits at least twice a year.

For each participant using $\geq 5$ chronically prescribed drugs, a yearly medication review was held by the GP, the nurse, and a pharmacist.

In addition, we developed multidisciplinary guidelines for 8 common geriatric syndromes, a guideline on advance care planning, procedure agreements for easy-to-access consultation by geriatric experts, and procedure agreements between primary and specialized care providers upon hospitalization and discharge. ${ }^{20}$

\section{Outcome Measurements}

Common baseline characteristics of the participants were expanded with a socioeconomic status score, a cognition score, and a frailty index. The socioeconomic status score was based on postal code areas and calculated based on income, employment, and education. ${ }^{26}$ A cognition score was based on a modified Mini-Mental State Examination. ${ }^{22}$ The frailty index was defined as the proportion of accumulated deficits. ${ }^{22,27}$ All baseline characteristics were included in the EASY-Care TOS step 2. Furthermore, the items constructing the primary and secondary outcomes were enclosed. Data were collected at baseline and after 12 months through a home visit by either a trained nurse (in the intervention arm) or a research assistant (in the control arm). Outcome assessors were blinded to previous measurements but, for pragmatic reasons, not to the intervention arm. Additional health care utilization data were extracted from the EMR at follow-up.

Independence in functioning in (instrumental) activities of daily living, measured with the validated Katz-15 index, ${ }^{28}$ was used as the primary participants' outcome. Quality of life [measured with the EuroQol $(\mathrm{EQ}-5 \mathrm{D}+\mathrm{C})$ instrument $]{ }^{29}$ mental health (measured with the 36-item RAND Short Form Survey [RAND-36]), ${ }^{30}$ health-related social functioning (measured with 1 question that was based on the social functioning subscale of the RAND-36), ${ }^{30}$ institutionalization, hospitalization, and mortality were chosen as secondary outcomes.

\section{Sample Size Calculation}

Based on a power of $80 \%$, a 2 -sided $\alpha$ of 0.05 , an assumed intracluster correlation coefficient (ICC) of $0.01,{ }^{31}$ and an expected loss to follow-up of $35 \%$, we calculated that we would be able to detect a clinically sufficient effect size of $>0.32$ on the Katz-15 index by including 50 participants from each of the 12 GP practices (total $\mathrm{N}=600$, assuming equal cluster sizes). Extended information on the sample size calculation was published in the study protocol. ${ }^{20}$

\section{Statistical Analysis}

Outcomes at the participants' level were analyzed with linear mixed-model analyses to account for the 
Table 1. Baseline Characteristics of Participants in the Intervention Group and Control Group

\begin{tabular}{|c|c|c|c|}
\hline Characteristics & CareWell Primary Care $(n=287)$ & Usual Care $(n=249)$ & $P$ Value for Difference \\
\hline Age (years), mean (SD) & $83.1(5.6)$ & $80.5(6.0)$ & .42 \\
\hline Female sex & $192(66.9)$ & $160(64.3)$ & .52 \\
\hline Living alone & $182(63.4)$ & $136(54.6)$ & .039 \\
\hline Socioeconomic status score, ${ }^{*}$ mean (SD) & $0.5(1.1)$ & $0.2(0.5)$ & $<.001$ \\
\hline Low level of education & $69(24.1)$ & $100(41.0)$ & $<.001$ \\
\hline Cognition score, ${ }^{\dagger}$ mean (SD) & $7.5(7.0)$ & $5.3(4.8)$ & $<.001$ \\
\hline Katz-15 index ${ }^{\ddagger}$ mean (SD) & $5.4(2.9)$ & $4.6(2.7)$ & .33 \\
\hline $\mathrm{EQ}-5 \mathrm{D}+\mathrm{C},{ }^{\S}$ mean $(\mathrm{SD})$ & $0.6(0.3)$ & $0.6(0.3)$ & .08 \\
\hline RAND-36 mental health ${ }^{\mathbb{I}}$ & $61.1(13.1)$ & $62.4(13.7)$ & .38 \\
\hline $\begin{array}{l}\text { Presence of health-related limitations in } \\
\text { social functioning }\end{array}$ & $178(64.3)$ & $88(37.1)$ & $<.001$ \\
\hline Frailty index, ${ }^{* *}$ mean $(\mathrm{SD})$ & $0.4(0.2)$ & $0.4(0.2)$ & .90 \\
\hline Presence of care complexity & $60(21.1)$ & $75(30.1)$ & .017 \\
\hline
\end{tabular}

Data are expressed as numbers (percentage) unless otherwise indicated.

*Socioeconomic status score was based on postal code areas (income, employment, and education); a higher score indicates more social disadvantage.

${ }^{\dagger}$ Based on a modified Mini-Mental State Examination (range, 0-28); a higher score indicates more cognitive problems.

${ }^{\ddagger}$ Katz-15 scores range from 0 to 15 ; a higher score indicates more dependence in (instrumental) activities of daily living.

${ }^{\S} \mathrm{EQ}-5 \mathrm{D}+\mathrm{C}$ scores range from -0.33 to 1.00 ; a higher score indicates a higher health-related quality of life.

"The 36-item RAND Mental Health questionnaire (RAND-36) scores range from 0 to 100; a higher score indicates better mental health.

"Based on the social functioning subscale of the RAND-36. Answers were dichotomized as the "absence of limitations" vs. the other categories indicating the "presence of limitations."

**The frailty index measures accumulated deficits (scale 0 to 1); a higher index suggests a more frail status.

EQ-5+C, EuroQuol instrument; SD, standard deviation.

clustering of participants within the GP practices. Outcome estimates were corrected for significant differences in baseline characteristics that correlated with the primary outcome, and for the baseline value of the outcome (in the case of secondary outcomes) by including these variables as covariates. Subgroup analyses compared outcome estimates for participants in the lowest, middle, and highest tertiles of age and Katz-15 index scores, and for participants with and without complex care.

Residential and nursing home admissions, hospital admissions, and mortality were analyzed with binary logistic regression with correction for baseline values of the Katz-15 index. In evaluating admissions and mortality, no correction for baseline characteristics and covariates was done, since the number of events was too small to perform a multilevel analysis and the calculated ICC was found to be negligibly low.

Baseline differences were analyzed using $t$ tests and $\chi^{2}$ tests. Tests were considered significant at $P<.05$. All statistical analyses were performed using SPSS software version 20 (IBM, Chicago, IL).

\section{Results}

\section{Sample Characteristics}

We included 536 participants: 287 in the intervention group and 249 in the control group. Baseline characteristics are shown in Table 1. Participants in the intervention group more often lived alone, had more health-related limitations in social functioning, more cognitive deficits, and more social disadvantage, and showed less complex care. These 5 characteristics correlated to the Katz-15 index score and were therefore used as covariates in our analyses. Furthermore, participants in the intervention group were higher educated.

We lost to follow-up 83 participants $(28.9 \%)$ in the intervention group and $84(33.7 \%)$ in the control group (Figure 1). The follow-up measurements therefore included 204 participants $(71.1 \%)$ in the intervention group and $165(66.3 \%)$ in the control group. Participants lost to follow-up in the intervention group were significantly older, more dependent in daily life, had more health-related limitations in social functioning, more cognitive deficits, more social disadvantage, and a more frail status, and were more educated compared with participants who were lost to follow-up in the control group. 
Figure 1. Flow diagram of practices and participants. GP, general practitioner.

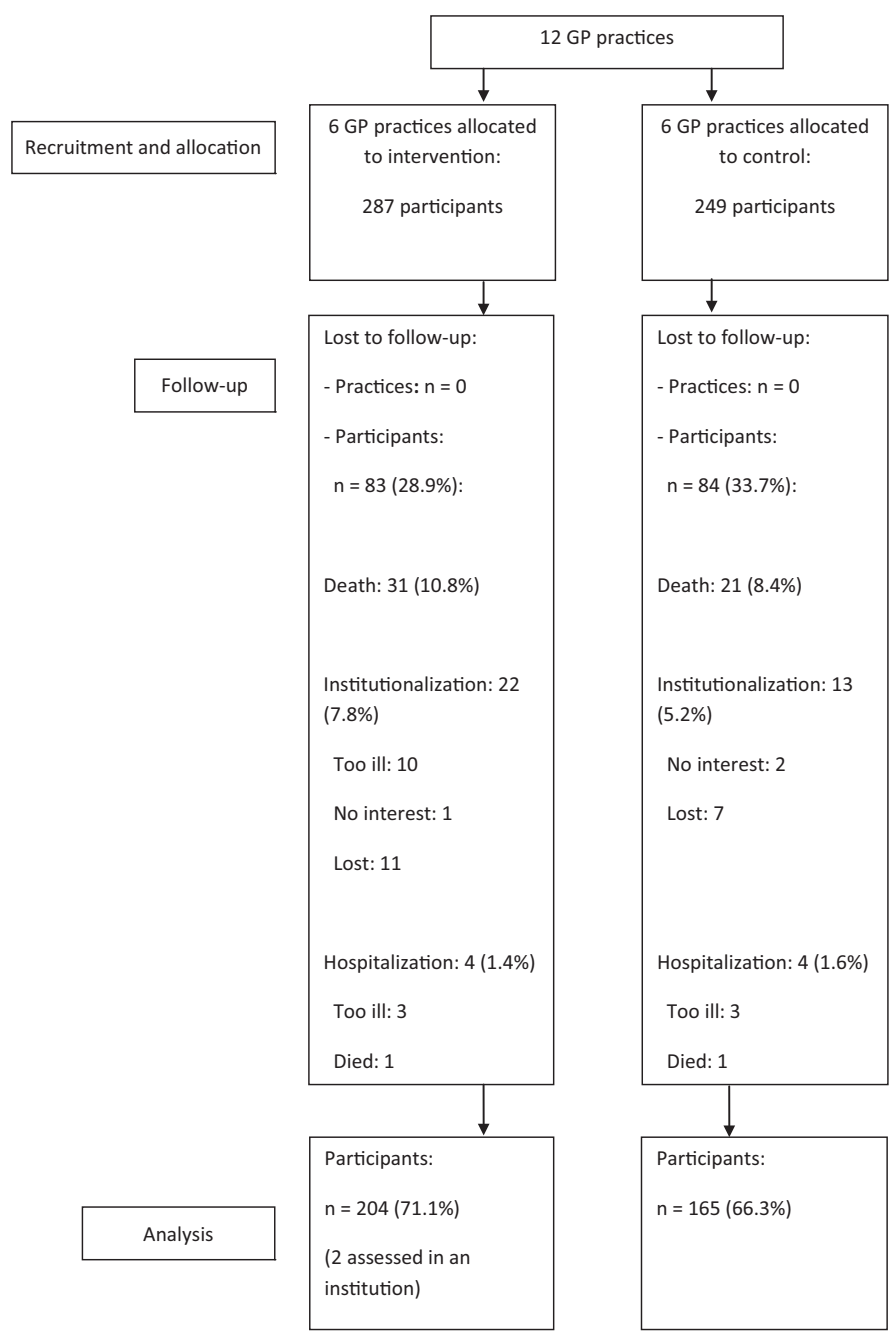

\section{Patient Outcomes}

The Katz-15 index score showed a greater increase, indicating more decline in functioning, in the intervention group compared with the control group. After correcting for clustering (with a calculated ICC of 0.05), relevant covariates, and the Katz-15 index score at baseline, no significant effects on functioning were found (Table 2). Moreover, we found no significant effects on quality of life, mental health, and health-related limitations in social functioning (Table 2). Subgroup analyses showed no mediating effects of age (divided into tertiles: $<80,80-85,>85$ years); baseline Katz-15 index scores (divided into tertiles; $<3,3-6,>6$ ); and the absence or presence of complex care, with the exception of small estimated intervention effects on quality of life $(-0.18$ (95\% CI -0.36 to $-0.00 ; P=$ $0.048)$ and on social functioning $(0.29$ (95\% CI 0.10 to $0.48 ; P=0.003)$ in the $80-85$ year-olds in favor of the control group (data not shown in tables). No differences in residential and nursing home admissions, hospital admissions, and mortality were found (Table 3).

\section{Discussion}

We found no effects of the CareWell primary care program on functioning, quality of life, mental health, health-related social functioning, institutionalization, hospitalization, and mortality among community-dwelling frail elderly people in Dutch primary care. A strength of this study is the inclusion of a large sample of frail elderly people well defined by professionals who were trained in the concept of frailty. In addition, the inclusion of motivated primary care professionals in the intervention group and the use of several tailored implementation strategies supported the optimal im- 
Table 2. Effects of the CareWell Primary Care Program on Primary and Secondary Outcomes

\begin{tabular}{|c|c|c|c|c|c|c|}
\hline \multirow[b]{2}{*}{ Outcome } & \multicolumn{2}{|c|}{$\begin{array}{c}\text { CareWell Primary Care* } \\
(\mathrm{n}=204)\end{array}$} & \multicolumn{2}{|c|}{ Usual Care $^{*}(\mathrm{n}=165)$} & \multirow[b]{2}{*}{$\begin{array}{l}\text { Estimated Intervention } \\
\text { Effect* }(95 \% \mathrm{CI})\end{array}$} & \multirow[b]{2}{*}{$P$ Value } \\
\hline & Baseline & $\begin{array}{l}\text { Change } \\
\text { at Follow-up }\end{array}$ & Baseline & $\begin{array}{l}\text { Change } \\
\text { at Follow-up }\end{array}$ & & \\
\hline Katz-15 index $^{\dagger}$ & $5.4(2.9)$ & $0.8(1.9)$ & $4.6(2.7)$ & $0.5(2.1)$ & $0.37(-0.1$ to 0.8$)$ & .10 \\
\hline $\mathrm{EQ}-5 \mathrm{D}+\mathrm{C}^{\ddagger}$ & $0.6(0.3)$ & $0.0(0.3)$ & $0.6(0.3)$ & $0.0(0.3)$ & $-0.031(-0.1$ to 0.0$)$ & .37 \\
\hline RAND-36 mental health ${ }^{\S}$ & $61.1(13.1)$ & $-0.28(13.6)$ & $62.4(13.7)$ & $-0.8(13.7)$ & $0.86(-2.3$ to 4.0$)$ & .56 \\
\hline $\begin{array}{l}\text { Health-related limitations in social } \\
\text { functioning }\end{array}$ & $1.5(1.4)$ & $-0.1(1.6)$ & $0.9(1.3)$ & $0.3(1.7)$ & $0.037(0.2-0.2)$ & .76 \\
\hline
\end{tabular}

Data are mean (standard deviation) unless otherwise indicated.

*Adjusted for clustering; baseline values of relevant covariates (living situation, health-related limitations in social functioning, cognition score, socioeconomic status score, and care complexity); baseline value of the Katz-15 index; and, in the case of secondary outcomes, baseline value of the outcome parameter.

${ }^{\dagger}$ Katz-15 scores range from 0 to 15 ; a higher score indicates more dependence in (instrumental) activities of daily living.

${ }^{\ddagger} \mathrm{EQ}-5 \mathrm{D}+\mathrm{C}$ scores range from -0.33 to 1.00 ; a higher score indicates a higher health-related quality of life.

${ }^{\S}$ The 36-item RAND Mental Health questionnaire (RAND-36) mental health scores range from 0 to 100; a higher score indicates better mental health.

"Based on the social functioning subscale of the RAND-36. Answers are dichotomized as the "absence of limitations" vs. the other categories indicating the "presence of limitations."

CI, confidence interval; EQ-5D+C, EuroQol instrument.

plementation and benefit of the program. The implementation of the program in everyday practice contributed to its external validity.

We also consider some weaknesses. First, significant baseline differences existed between the study groups. These may have resulted from the cluster design that was used to prevent the spillover of intervention effects. ${ }^{19}$ Moreover, differences in the appraisal of participants' frailty by the GPs in both groups may have contributed. However, all professionals were trained in the concept of frailty and the use of the EASY-Care TOS to minimize these kinds of imbalances. Although we corrected for baseline differences, they may still have affected our results. Second, the allocation of motivated professionals to the intervention group might have led to differences in the quality of care delivery between groups in favor of the intervention group. However, since we found no between-group differences in effects on functioning and secondary outcomes, it is unlikely that the allocation procedure led to bias in favor of the intervention. Professionals in both groups used the EasyCare-TOS instrument, which may have led to "enhanced" usual care in the control group. ${ }^{32} \mathrm{We}$ tried to minimize this effect by instructing the control practices not to start new activities related to the intervention, such as improved collaboration, making care plans, and starting medication reviews during the study period. Third, outcome assessors were not blinded to the intervention since this was not feasible. Last, participants with the least degree of functioning (ie, higher Katz-15 index scores) were more often lost to follow-up in the intervention group. However, since we assume that these participants would have the least potential to benefit, an effect in favor of the intervention group without this loss to follow-up is unlikely.

In the past 20 years, several studies have been conducted with programs targeting improving functioning and preventing institutionalization and hospitalization in community-dwelling frail elderly

Table 3. Admissions and Mortality During Follow-up

\begin{tabular}{lcccc}
\hline Outcome & $\begin{array}{c}\text { CareWell Primary Care } \\
(\mathrm{n}=204)\end{array}$ & $\begin{array}{c}\text { Usual Care } \\
(\mathrm{n}=165)\end{array}$ & Odds Ratio (95\% CI) $P$ Value \\
\hline Residential and nursing home admissions & $24(8.3)$ & $13(5.2)$ & $1.32(0.64-2.71)$ & .46 \\
Hospital admissions & $52(18.1)$ & $57(22.9)$ & $0.74(0.48-1.14)$ & .17 \\
Mortality & $31(10.8)$ & $21(8.4)$ & $1.13(0.61-2.08)$ & .70 \\
\hline
\end{tabular}

Data are $\mathrm{n}(\%)$ unless otherwise indicated. CI, confidence interval. 
people. These studies have heterogeneous designs and settings and have yielded inconsistent results. ${ }^{10-12}$ For example, Bernabei et $\mathrm{al}^{33}$ showed that an integrated community care program with standardized multidisciplinary meetings between the GP, nurse, geriatrician, and social worker reduced functional decline, institutionalization, and hospitalization. However, a home-based care management program delivered by a nurse and a social worker in collaboration with a geriatric multidisciplinary team, complementary to care delivered by the GP, showed no effects on functioning. ${ }^{34}$ More recently, Metzelthin et $\mathrm{al}^{35}$ found no effect on disability after introducing a program based on meetings between the GP and practice nurse, care planning, and regular monitoring and follow-up. Despite our efforts to optimally implement a fully integrated care and welfare program, we found no evidence for the effectiveness of this program in the prevention of functional decline, institutionalization, or hospitalization.

In addition to the methodological drawbacks, there are some other potential explanations for the absence of effects of the CareWell primary care program. First, the outcome measures used might not be specific and responsive enough in our targeted population. Although the Katz-15 index is applied in the vast majority of studies of functional decline and reliably predicts adverse health outcomes among community-dwelling frail elderly people, ${ }^{36,37}$ it might not be responsive to change in individual elders within a limited time span. Moreover, the EASY-Care TOS instrument identifies health risks related to functioning as well as to psychosocial and environmental domains that are negatively influenced by frailty. Subsequently, the programs' interventions and goals are highly individualized and heterogeneous. Outcome measures that are more person- and goal-centered (eg, goal-attainment scaling) might better measure the effectiveness of our intervention. ${ }^{38}$ Second, it is widely recognized that complex interventions are often not delivered or adhered to as intended, ${ }^{39-41}$ which we accept as part of the outcome given the pragmatic nature of our study. Moreover, the follow-up period of 12 months may be too short to establish effective multidisciplinary collaborations, a true transition toward integrated care, ${ }^{41}$ and to achieve measurable effects on patient outcomes. A third explanation may be that the targeted population was too frail for the interventions to be effective in preventing adverse health outcomes. On the other hand, frail elderly people may appraise the boundaries of functional decline differently, leading to a willingness to adhere to preventive interventions at too late a stage, leading to low adherence at the participant level. A last explanation relates to the Dutch health care system, in which the GP already has a strong position and a central role in delivering geriatric care, often in collaboration with practice nurses, and facilitated by high-quality EMRs. ${ }^{7}$ This suggests that limited room for improvement exists in comparison to health care settings in which primary care is less well organized. On the other hand, our results may hold external validity to health care settings in which collaboration can be set up between health care and welfare and between primary and geriatric care.

\section{Conclusion}

We found no beneficial effects of our CareWell primary care program among community-dwelling frail elderly people in Dutch primary care. Current evidence is insufficient to advocate large-scale implementation of this multicomponent integrated primary care program. Further (longitudinal) studies are needed on the different trajectories of frailty and the most efficient timing of interventions. Moreover, research is needed on the validity and applicability of goal-oriented outcome measures in the field of geriatric research.

The authors are grateful to all participants and health care professionals who were involved in the study. Furthermore, the authors thank all professionals, volunteers, and health care organizations that are involved in Netwerk 100 (http:// www.netwerk100.nl) for their contributions to the development of the CareWell primary care program.

\section{References}

1. De Lepeleire J, Iliffe S, Mann E, Degryse JM. Frailty: an emerging concept for general practice. Br J Gen Pract 2009;59:e177-82.

2. Morley JE, Vellas B, van Kan GA, et al. Frailty consensus: a call to action. J Am Med Dir Assoc 2013;14:392-7.

3. Hoogendijk EO, Muntinga ME, van Leeuwen KM, et al. Self-perceived met and unmet care needs of frail older adults in primary care. Arch Gerontol Geriatr 2014;58:37-42.

4. Clegg A, Young J, Iliffe S, Rikkert MO, Rockwood K. Frailty in elderly people. Lancet 2013;381: 752-62.

5. Clarkson P, Brand C, Hughes J, Challis D. Integrating assessments of older people: examining evidence 
and impact from a randomised controlled trial. Age Ageing 2011;40:388-91.

6. Doran T, Roland M. Lessons from major initiatives to improve primary care in the United Kingdom. Health Aff (Millwood) 2010;29:1023-9.

7. van Weel C, Schers H, Timmermans A. Health care in the Netherlands. J Am Board Fam Med 2012; 25(Suppl 1):S12-7.

8. Koopmans RT, Lavrijsen JC, Hoek JF, Went PB, Schols JM. Dutch elderly care physician: a new generation of nursing home physician specialists. J Am Geriatr Soc 2010;58:1807-9.

9. Boeckxstaens P, De Graaf P. Primary care and care for older persons: position paper of the European Forum for Primary Care. Qual Prim Care 2011;19: 369-89.

10. Beswick AD, Rees K, Dieppe P, et al. Complex interventions to improve physical function and maintain independent living in elderly people: a systematic review and meta-analysis. Lancet 2008;371: $725-35$.

11. Eklund K, Wilhelmson K. Outcomes of coordinated and integrated interventions targeting frail elderly people: a systematic review of randomised controlled trials. Health Soc Care Community 2009;17:447-58.

12. Low LF, Yap M, Brodaty H. A systematic review of different models of home and community care services for older persons. BMC Health Serv Res 2011; 11:93.

13. Hajjar ER, Cafiero AC, Hanlon JT. Polypharmacy in elderly patients. Am J Geriatr Pharmacother 2007; 5:345-51.

14. Maher RL, Hanlon J, Hajjar ER. Clinical consequences of polypharmacy in elderly. Expert Opin Drug Saf 2014;13:57-65.

15. Koberlein J, Gottschall M, Czarnecki K, Thomas A, Bergmann A, Voigt K. General practitioners' views on polypharmacy and its consequences for patient health care. BMC Fam Pract 2013;14:119.

16. Hilmer SN, Gnjidic D, Le Couteur DG. Thinking through the medication list - appropriate prescribing and deprescribing in robust and frail older patients. Aust Fam Physician 2012;41:924-8.

17. NHG Standpunt Toekomstvisie Huisartsenzorg. Huisartsgeneeskunde voor ouderen; 'Er komt steeds meer bij'. Utrecht: Nederlands Huisartsen Genootschap; 2007.

18. Godwin M, Ruhland L, Casson I, et al. Pragmatic controlled clinical trials in primary care: the struggle between external and internal validity. BMC Med Res Methodol 2003;3:28.

19. Campbell MK, Piaggio G, Elbourne DR, Altman DG, Group C. Consort 2010 statement: extension to cluster randomised trials. BMJ 2012;345:e5661.

20. Ruikes FG, Meys AR, van de Wetering G, et al. The CareWell-primary care program: design of a cluster controlled trial and process evaluation of a complex intervention targeting community-dwelling frail elderly. BMC Fam Pract 2012;13:115.

21. van Kempen JA, Schers HJ, Jacobs A, et al. Development of an instrument for the identification of frail older people as a target population for integrated care. Br J Gen Pract 2013;63:e225-31.

22. van Kempen JA, Schers HJ, Melis RJ, Olde Rikkert MG. Construct validity and reliability of a two-step tool for the identification of frail older people in primary care. J Clin Epidemiol 2014;67:176-83.

23. Keiren SM, van Kempen JA, Schers HJ, et al. Feasibility evaluation of a stepped procedure to identify community-dwelling frail older people in general practice. A mixed methods study. Eur J Gen Pract 2014;20:107-13.

24. de Jonge P, Huyse FJ, Stiefel FC. Case and care complexity in the medically ill. Med Clin North Am 2006;90:679-92.

25. Robben SH, Perry M, Huisjes $M$, et al. Implementation of an innovative web-based conference table for community-dwelling frail older people, their informal caregivers and professionals: a process evaluation. BMC Health Serv Res 2012;12:251.

26. Knol FA. Van hoog naar laag; van laag naar hoog. Den Haag: Elsevier; 1998. Available from: http:// www.scp.nl/Publicaties/Alle_publicaties/Publicaties_ 1998/Van_hoog_naar_laag_van_laag_naar_hoog. Accessed January 25, 2016.

27. Mitnitski AB, Mogilner AJ, Rockwood K. Accumulation of deficits as a proxy measure of aging. ScientificWorldJournal 2001;1:323-36.

28. Weinberger M, Samsa GP, Schmader K, Greenberg SM, Carr DB, Wildman DS. Comparing proxy and patients' perceptions of patients' functional status: results from an outpatient geriatric clinic. J Am Geriatr Soc 1992;40:585-8.

29. Krabbe PF, Stouthard ME, Essink-Bot ML, Bonsel GJ. The effect of adding a cognitive dimension to the EuroQol multiattribute health-status classification system. J Clin Epidemiol 1999;52:293-301.

30. VanderZee KI, Sanderman R, Heyink JW, de Haes H. Psychometric qualities of the RAND 36Item Health Survey 1.0: a multidimensional measure of general health status. Int J Behav Med 1996;3:104-22.

31. Campbell MK, Fayers PM, Grimshaw JM. Determinants of the intracluster correlation coefficient in cluster randomized trials: the case of implementation research. Clin Trials 2005;2:99-107.

32. Smelt AF, van der Weele GM, Blom JW, Gussekloo J, Assendelft WJ. How usual is usual care in pragmatic intervention studies in primary care? An overview of recent trials. Br J Gen Pract 2010;60: e305-18.

33. Bernabei R, Landi F, Gambassi G, et al. Randomised trial of impact of model of integrated care and case management for older people living in the community. BMJ 1998;316:1348-51. 
34. Counsell SR, Callahan CM, Clark DO, et al. Geriatric care management for low-income seniors: a randomized controlled trial. JAMA 2007;298:2623-33.

35. Metzelthin SF, van Rossum E, de Witte LP, et al. Effectiveness of interdisciplinary primary care approach to reduce disability in community dwelling frail older people: cluster randomised controlled trial. BMJ 2013;347:f5264.

36. Buurman BM, van Munster BC, Korevaar JC, de Haan RJ, de Rooij SE. Variability in measuring (instrumental) activities of daily living functioning and functional decline in hospitalized older medical patients: a systematic review. J Clin Epidemiol 2011; 64:619-27.

37. Laan W, Zuithoff NP, Drubbel I, et al. Validity and reliability of the Katz-15 scale to measure unfavorable health outcomes in community-dwelling older people. J Nutr Health Aging 2014;18:848-54.

38. Rockwood K, Howlett S, Stadnyk K, Carver D, Powell C, Stolee P. Responsiveness of goal attain- ment scaling in a randomized controlled trial of comprehensive geriatric assessment. J Clin Epidemiol 2003;56:736-43.

39. Metzelthin SF, Daniëls R, van Rossum E, et al. A nurse-led interdisciplinary primary care approach to prevent disability among community-dwelling frail older people: a large-scale process evaluation. Int J Nurs Stud 2013;50:1184-96.

40. Stijnen MM, Jansen MW, Duimel-Peeters IG, Vrijhoef HJ. Nurse-led home visitation programme to improve health-related quality of life and reduce disability among potentially frail community-dwelling older people in general practice: a theory-based process evaluation. BMC Fam Pract 2014;15:173.

41. Muntinga ME, Van Leeuwen KM, Schellevis FG, Nijpels G, Jansen A. From concept to content: assessing the implementation fidelity of a chronic care model for frail, older people who live at home. BMC Health Serv Res 2015;15:18. 